\title{
Political Theorizing and Policy Implications: The Case of a Rawlsian Approach to Multicultural Education
}

\author{
Masakazu Matsumoto \\ Shimane University \\ Japan
}

This article provides a philosophical foundation for the legitimacy of multicultural education by developing the analyses of Rawlsian political philosophy. For Rawls the most important primary good is that of self-respect, and this can be reinterpreted to make a convincing argument for multicultural education, provided that it has a strong connection to cultural minorities' sense of self-respect. After clarifying this connection, this article addresses the objection raised against the idea of equating multicultural education with a social basis of students' self-respect. It ends with a brief overview of a recent example of multicultural education in Japan.

\author{
Rawls on the Social Bases of Self-Respect \\ Multicultural Education as a Social Basis of Self-Respect \\ The Indeterminacy Objection \\ The Case of Immigrant Children in Japan \\ Conclusion \\ Notes \\ References
}

It is well known that John Rawls' A Theory of Justice has had widespread influence in Anglo-American political philosophy since its publication in 1971. The book has been scrutinized by multiple advocates and critics since then, and the impact of this intellectual trend is sometimes even called the "Rawls industry." This article is an attempt to extend part of the products within this "industry" to the field of multicultural education.

Rawlsian political philosophy has so far been evaluated from two separate viewpoints: multiculturalism and education. Some attempts have been made to apply it to the analysis of multicultural questions (e.g., Kymlicka, 1989); other attempts have been made to use it to address current civic educational problems (e.g., Macedo, 2003). This article differs from these previous studies in the sense that it places its primary focus on the issue of multicultural education.

According to Banks' (2002) formulation, multicultural education contains the following five dimensions: content integration, the knowledge construction process, prejudice reduction, equity pedagogy, and an empowering school culture and social structure. It has emerged as a new research field since the Civil Rights Movement of the 1960s and 1970s in the United States. The 
multicultural education approach is now spread all across the world because it provides one of the most promising methods by which groups belonging to different cultures, races, religions and social classes can coexist with each other in a peaceful and interactive way.

There are, however, also a number of criticisms that have been voiced mainly by conservatives since the 1980s, especially in the United States. Multicultural education, so the critics claim, destroys the sense of civic solidarity, propagates value relativism and nihilism among students, and turns schools and colleges into arenas of ethnic and racial outbursts (Bloom, 1988; Huntington, 2004; Schlesinger, 1998). The heated debate raised by American intellectuals over the legitimacy of multicultural education has even been described as "culture wars" (Gitlin, 1995).

This article does not directly address this debate. Instead, it seeks to provide a philosophical foundation for the legitimacy of multicultural education by developing the analyses of Rawlsian political philosophy. Namely, the aim of this article is to show that we can find one justificatory reason for multicultural education in Rawls' arguments in A Theory of Justice, though he does not explicitly refer to the issue. The hypothesis that will be explored here is that if one accepts the validity of his argument on "the social basis of self-respect," then one will also come to accept the validity of multicultural education since it can be regarded as one of the main bases of minority students' affirmative self-identity.

This article will be divided into four sections. First, I reconstruct Rawls' argument and see what he and his followers think is important for ensuring people's sense of self-respect. Second, I apply this Rawlsian doctrine on the social bases of self-respect to the domain of ethnic culture and restate it as a strong argument for the practice of multicultural education. Third, I look at an objection raised against the idea of equating multicultural education with a social basis of students' self-respect. Finally, I introduce a short example of the practice of multicultural education for immigrant children in contemporary Japan.

\section{Rawls on the Social Bases of Self-Respect}

A promising way to approach the issue of multicultural education from a Rawlsian viewpoint is to pay attention to his (not always clearly delineated) argument in A Theory of Justice about the "social bases of self-respect." 1 In this section, I show why guaranteeing the "social bases of self-respect" for everyone is important in Rawlsian political philosophy and clarify what are supposed to be necessary conditions for people to maintain their self-respect.

Rawls' theory of justice consists of his Two Principles. The First Principle guarantees equal basic liberties like the right to vote, freedom of speech and assembly, liberty of conscience and freedom of thought, freedom of the person, and the concept of the rule of law. The Second Principle includes the Difference Principle, which assures a fair distribution of income and wealth (Rawls, 1971).2 There is a third distributive good, however, that Rawls himself refers to at several 
points and yet does not appear explicitly in the above Two Principles of justice: a sense of one's own worth, or that of self-respect.

Self-respect includes a deep conviction that one's plan of life is worth carrying out and a confidence in the ability to fulfill one's intention. Though not addressed directly in his Two Principles, according to Rawls, "Perhaps the most important primary good is that of self-respect" (Rawls, 1971, p. 440) since "without it nothing may seem worth doing, or if some things have value for us, we lack the will to strive for them" (1996, p. 318). These quotes imply that all the other social primary goods, including civil/political and economic goods, are to be distributed in the way that best ensures the sense of self-respect that the beneficiaries have. Indeed, in a section entitled "The Main Grounds for the Two Principles of Justice," he writes that the main reason for endorsing the Two Principles of justice is that they make one's respect for others possible and that this in turn leads to the experience of respecting oneself (Rawls, 1971). This means that where they fail to provide the appropriate bases of self-respect, the Two Principles of justice themselves are hardly justified. Since a sense of selfrespect plays so important a role in Rawls' theory of justice in this way, he even states that "the parties in the original position would wish to avoid at almost any cost the social conditions that undermine self-respect" (Rawls, 1971, p. 440). In short, as Eyal (2005) points out, it is not exaggerated to say that "the 'covert' principle [that requires a maximum of each equally distributed social basis of selfrespect] is lexically prior to both other principles of justice" (pp. 199-200). Selfrespect seems here to represent the critical point when discussing an appropriate distributive form of other social primary goods.

Now, what is needed for this important good of self-respect to be ensured? Rawls subdivides the necessary conditions into "associational conditions" and "framework conditions" (Cohen, 1989, p. 737). The former are related to the domain of the non-basic structure of society, which includes offices, labor unions, churches, and families, whereas the latter are related to the domain of the basic structure of society itself. Given that the main subject of Rawlsian principles of justice is limited to the basic structure of society (Rawls, 1971), the latter framework conditions are the crux of the matter pursued in this article. ${ }^{3}$

Let us consider them one by one. Rawls presents two elements as the associational conditions of self-respect. The first one is that one's plan of life must satisfy the Aristotelian Principle that requires the person's plan of life to be accompanied with natural capacities to carry it out in a great and complex way so as not to seem dull and flat (i.e., individual endorsement). The second element is that it should be evaluated and esteemed adequately by others, which means that self-respect is to be based not on self-complacency but on social respect and recognition (i.e., social confirmation) (Rawls, 1971, p. 440). ${ }^{4}$

The question is: What conditions does the basic structure of society need to satisfy to maintain the aforementioned associational conditions? With respect to this question, Rawls seems to think that only the First Principle that determines the fair distribution of civil/political liberties is relevant to ensuring the social bases of self-respect: "In a well-ordered society then self-respect is secured by 
the public affirmation of the status of equal citizenship for all; the distribution of material means is left to take care of itself in accordance with the idea of pure procedural justice" (Rawls, 1971, p. 545). The Second Principle, which determines the fair distribution of economic goods, plays a very limited role as a framework condition of self-respect. In short, people are assumed to preserve their sense of self-respect once they have acquired equal civil/political liberties, regardless of the remaining economic inequality.

Rawls' assumption outlined above has met with many criticisms. Indeed, his suggestion that economic inequality does not matter for self-respect insofar as equal civil/political liberties are guaranteed seems practically unsupportable. Zaino (1998), for instance, denounces Rawls as no more than a defender of a bourgeois class order in the sense that he disregards the possibility that economic factors may play an important role in enhancing the less well-off's selfdignity. McKinnon (2003) develops a more sympathetic interpretation of $A$ Theory of Justice and suggests that we can find in it a theoretical foundation for "universal basic income" as a social basis of self-respect. Gutmann (1980) also argues that if the less well-off's sense of self-respect is severely threatened by economic disparities, the priority of self-respect as a primary good would warrant a more equal economic distribution (p. 137). ${ }^{5}$ Taken together, they suggest that people's economic conditions as well be taken into consideration when discussing the proper bases of self-respect.

\section{Multicultural Education as a Social Basis of Self-Respect}

As we have seen in the last section, Rawls himself keeps his focus solely on the protection of civil/political liberties as the social basis of self-respect, while his followers turn their focus to the value of economic goods. Curiously enough, however, neither of them has paid much attention to the factor of culture as a source of one's sense of self-respect.

Multiculturalists were the ones who introduced the dimension of culture to Rawls' argument on "the social basis of self-respect." Though not unanimous in their details, they are generally united in emphasizing the basic fact that, since one's cultural membership profoundly affects the person's identity-formation, being affirmed in the virtue of a person's cultural background does play a crucial role in the person's self-image. As Bikhu Parekh argues,

An individual is not a free-floating atom but a member of a specific community and his identity is at once both personal and special. His selfrespect is therefore necessarily tied up with, and partly grounded in, the general respect for his community.... Human beings feel ontologically insecure and fail to develop the vital qualities of self-respect, selfconfidence and a sense of their own worth if they are constantly insulted, ridiculed, subjected to snide innuendoes, and made objects of crude jokes on the basis of their race, color, gender, nationality or social and economic background. (Parekh, 1990, p. 705) 
Thus it seems reasonable to say that cultural recognition serves an important function as a social basis of self-respect as well as the achievement of civil/political liberties and the pursuit of economic equalization. Precisely because "the parties in the original position would wish to avoid at almost any cost the social conditions that undermine self-respect" in Rawls' own assumption, they would almost certainly want the kind of Rawlsian principle of justice that gives proper recognition to their culture (Kymlicka, 1989, p. 166). When the culture they belong to is susceptible to the influence of stereotyping and prejudice, this is quite likely to have a negative impact on their self-identity. Thus many scholars have come to the same conclusion that the positive affirmation of minority cultures must be regarded as an important basis of their self-respect in a Rawlsian sense (Tully, 1995; Lægaard, 2005; McKinnon, 2006; Weinstock, 1994). Culture itself is a source of one's identity and self-respect and therefore should be taken into account to ensure the person's sense of self-worth. As Seglow (1998) points out, "Principles of cultural recognition can enter a liberalism which is Rawlsian if not Rawls's through the important primary good of selfrespect" (p. 965).

This leads us to realize one important thing in the field of education: if a cultural minority member's self-respect is "necessarily tied up with the general respect for his community," then this can also be an appropriate reason for Rawlsian political philosophers to accept the legitimacy of multicultural education (see also Moses, 1997). This does not mean that the primary aim of multicultural education must be to enhance minorities' feeling of self-respect. As Asante (1991) rightly explains, its primary aim is nothing but "to provide accurate information" (p. 270). Still, as he points out in the same paragraph, multicultural education has its "by-products," often resulting in the development of minority members' self-respect: "African Americans who are often as ignorant as whites about African achievements adjust their attitudes about themselves once they are exposed to new information" (p. 270). To summarize, provided that adopting multicultural education has some positive effects on cultural minorities' sense of self-respect, it can legitimately be seen as an appropriate part of what social justice requires in a Rawlsian sense.

\section{The Indeterminacy Objection}

So far this article has presented a multicultural interpretation of $A$ Theory of Justice and outlined a prima facie justificatory reason for adopting multicultural education as a social basis of self-respect. We need, in this section, to consider the following objection raised against the above judgment: Is the connection between multicultural education and the social bases of self-respect really so crucial? There are, indeed, some scholars who doubt the possibility of interpreting multicultural education as a firm basis of minority members' selfidentity.

The upshot of these scholars' arguments is that overemphasizing the connection between culture and self-respect can result in neglecting or even 
stifling the other possible bases of self-respect. It may be the case that people's sense of self-respect depends upon many other non-cultural sources. Rawls mentioned civil/political conditions and his followers argued economic conditions as the "social bases of self-respect." Thus, so the objection goes, promoting multicultural education does not always constitute a panacea for "perhaps the most important primary good" even in a Rawlsian well-ordered society.

For example, Waldron (1996) stated that "an attack on P in virtue of her ethnicity or cultural background cannot automatically be assumed to be an implicit attack on another person with the same background, for we cannot assume that a common cultural heritage has played the same role in the constitution of their respective identities" (pp. 113-114). Different persons attach different values to their own culture. It is then not always appropriate to suppose that their personal identity is closely tied up to their group identity, according to Waldron. Therefore, "What the attack on $\mathrm{P}$ does to the other person's dignity and self-respect will depend (at least in part) on what the latter has made for herself of the relations between the culture they share and the communities and cultures that surround them" (p. 114). Even where they find themselves in a disadvantaged position in terms of their cultural backgrounds, people would still be able to feel their own worth and value if they have a successful experience in such non-cultural fields as their academic record, sports, the activities of student union, and so on. From this point of view, Schlesinger (1998) is opposed to the excessive zeal of multicultural education and questions it as follows: "As for selfesteem, is this really the product of ethnic role models and fantasies of a glorious past? Or does it not result from the belief in oneself that springs from achievement, from personal rather than from racial pride?" (p. 98). Multicultural education may sometimes be needed as a means of providing the social bases of self-respect, but not always. How to identify the various sources of self-respect is a difficult question, but the sure thing is that we need to pay a lot more attention to many social and educational factors other than culture in ensuring what students really want to maintain their positive sense of self-identity.

What the above-described objection makes clear is the indeterminacy that surrounds the social psychological concept of "self-respect." One person's source of self-respect may be indifferent, or even hostile, to another person's self-respect. Thus the indeterminacy objection tells us that addressing how education can play any role in shaping students' sense of self-respect is in fact a far more complex issue than first imagined. As Spinner-Halev (2001) points out, "The social bases for self-respect are myriad.... There are so many, and sometimes contradictory, ways to try to ensure self-respect" (p. 92).

As is suggested by Waldron (1996) and Schlesinger (1998), the implementation of multicultural education is likely to fall within these "contradictory ways." Thus, even if it is admitted that Rawls' theory of justice is in fact governed by the "covert" principle that requires a maximum of each equally distributed social basis of self-respect, this does not by itself guarantee a "happy wedding" of Rawlsian political philosophy and multicultural education. To evaluate this we need to know more about the complex social psychological 
processes of self-identity formation (Caney, 2002; Lægaard, 2005). A philosophical justification for multicultural education seems, in short, to need to be accompanied with empirical evaluations.

\section{The Case of Immigrant Children in Japan}

As we saw in the last section, we need further empirical studies in the field of social psychology to see if multicultural education can be regarded as a relevant source of students' self-respect. This article cannot offer definitive answers to this question. Instead, before closing this article, I shall give a brief example of the practice of multicultural education in contemporary Japan and indicate one of its likely effects on the sense of self-respect of ethnic minority school children.

Japan has so far been generally regarded as one of the exceptionally rare states where one nation lives in one state-the so-called "myth of the homogeneous nation" (Oguma, 1995). This does not, of course, reflect the reality. The fact is that there live alongside the majority Japanese race (which is called "Yamato") many different kinds of ethnic minorities. First of all, there are the Ainu people in Hokkaido and the Ryukyu people in Okinawa, both of whom were historically integrated into Japan as the result of past aggressions and annexations. 6 Second, there are many ethnic Korean residents and their descendants, who had to emigrate in the course of Japanese colonization that started in 1910. Third, there are various other immigrant groups who came to Japan voluntarily especially since the beginning of the Japanese high economic growth period in the 1960s. Though still not so multicultural as European and North American countries, contemporary Japan is certainly a far more heterogeneous society than usually expected. ${ }^{7}$

Especially the third category of immigrants, those who moved to Japan voluntarily in the 1960s, has drastically increased in number since the partial amendment of the Immigration Control and Refugee Recognition Act in 1989. The number of foreign residents registered in Japan amounted to about $2,000,000$ at the end of 2005 , which corresponded to $1.57 \%$ of the whole population in Japan and reached a new high. The rate of population growth of foreign residents over the last 10 years is $47.7 \%$ while the rate of total population growth in Japan is only 1.7\% (Japan Immigration Association, 2006, p. 3). ${ }^{8}$ The most recent immigration figures show that the number of foreign residents had increased to some 2,134,000 at the end of 2010 .

These trends have created a host of new difficulties in educational contexts. An especially serious matter is the increase of new ethnic minority children who are experiencing some language difficulty in Japanese schools. According to the statistics disclosed by the Ministry of Education, the number of foreign students who need a special curriculum of Japanese amounts to about 20,000 (MEXT, 2006). 9 The Japanese language is composed of Chinese characters (ideograms) and of Japanese characters (phonograms) in complex ways, thus it is not easy for immigrant children to learn it as a second language. 
Regrettably, most of them do not enjoy good school circumstances for their educational needs, and many of them are confronted with such problems as alienation and exclusion in the classroom, poor school performance, and even refusal to go to school.

For instance, a teacher who is teaching a Japanese class in an elementary school in Osaka reports that the foreign students from China, Vietnam, and Thailand in his class shared common problems such as disturbing the class, giving up their future dreams, and hesitating to speak their mother tongues. It was, he says, because Japan's conventional school curriculum had adopted the submersion "sink or swim" method in language education and aimed at the wholesale "Japanization" of immigrant children.

A series of reforms were undertaken. The Ministry of Education decided to amend the Course of Study in 1999 and established the Periods for Integrated Study to provide students with an interdisciplinary education for the deeper understanding of multicultural coexistence. Responding to this, the elementary school in Osaka mentioned above created a new mother tongue classroom and began to engage in a further promotion of "Minzoku Gakkyu" (Nation Club) after school hours. This attempt is designed to contribute to the general advancement of learning by introducing immigrants' own cultural heritages (their languages, plays, traditional music, cooking, and sports) as part of the school curriculum. Consequently, their teacher records that foreign students who used to encounter various problems have rediscovered their self-respect in a dramatic way (Morisako, 2005). By attending the mother tongue classroom and "Minzoku Gakkyu," they have become proud of their own ethnic backgrounds, developed an intergenerational solidarity, and increased their willingness to learn. The same teacher ends with the remark that "establishing the mother tongue education system ... is the only way to open the door to the future dreams of newcomer children" (p. 42).

\section{Conclusion}

This article has focused on the question of whether and how multicultural education can legitimately be regarded as a social basis of self-respect in Rawlsian political philosophy. First, I reconstructed Rawls' own argument on the idea of the "social bases of self-respect" and then looked at the recent attempts to apply it to the realm of ethnic culture in the second section. In the third section, I examined the indeterminacy objection that is leveled against the trend of overemphasizing the role of multicultural education as a social basis of selfrespect. We need further empirical studies to evaluate the philosophical claim presented in the first half of the article that multicultural education can play the role of ensuring minorities' sense of self-worth. A recent Japanese example referred to in the final section is a sketchy one and cannot be easily generalized. However, the accumulation of knowledge from such empirical cases can contribute to a deeper understand of the impact of multicultural education on minority students' self-respect . 10 This does not mean, however, that constructing 
philosophical theories is of little use. On the contrary, it is actually very informative when we think about why it is at all important to focus on the concept of self-respect in addressing the still controversial issue of multicultural education.

\section{Notes}

1. In this article, I shall use the words "self-respect" and "self-esteem" interchangeably, though I understand they are sometimes conceptualized as distinct and separate. The former tends to be used by moral philosophers, the latter by psychologists (Dillon, 1995, p. 30). Rawls himself does not distinguish the two concepts in the original edition of $A$ Theory of Justice but explicitly states in a later work that it should be self-respect, not self-esteem, which he thinks should be guaranteed in his principles of justice (Rawls, 1996). In fact, the word "self-esteem" is replaced with the word "self-respect" in the revised edition published in 1999.

2. "Primary goods" are the things that Rawls (1971) presents as "some objective grounds for these comparisons, ones that men can recognize and agree to" (p. 9). Once we try to determine the principle of distributive justice that is fair to those persons with different endowments and different life plans, we need to have some objective measures or scales to judge who are more and who are less advantaged. Thus "primary goods....are things which it is supposed a rational man wants whatever else he wants," and they are tentatively identified as "rights and liberties, opportunities and powers, income and wealth," and "a sense of one's own worth" (p. 92).

3. "For us the primary subject of justice is the basic structure of society, or more exactly, the way in which the major social institutions distribute fundamental rights and duties and determine the division of advantages from social cooperation" (Rawls, 1971, p. 7).

4. I borrow the terms "individual endowment" and "social confirmation" from Kymlicka (1989, pp. 61-63).

5. In another book Rawls (1999) mentioned the possibility that economic disparities may be experienced as stigma and cause the loss of less well-off people's sense of self-respect.

6. The former were forced to assimilate into Japan as the Meiji Government decided to establish the Development Commission in Hokkaido in 1869, and the latter were forced to become a part of Japan through the Ryukyu Abolition in 1872.

7. As to the classification of ethnic minorities living in Japan, see Peng-Er (2005, pp. 227-232).

8. This figure is the sum total of ethnic Koreans (or oldcomers) and voluntary immigrants and their families (or newcomers). The former accounts for nearly $30 \%$ of the total number. 
9. About $36 \%$ of those children speak Portuguese as their native language, $21 \%$ speak Chinese, and 15\% speak Spanish.

10. For some scientific reports that indicate the positive relationship between multicultural education and ethnic members' sense of self-respect, see Baker (2001) and Hermes (2005).

\section{References}

Asante, M. K. (1991). Multiculturalism: An exchange. The American Scholar, 60(2), 267-276.

Baker, Colin (2001). Foundations of bilingual education and bilingualism. Clevedon, UK: Multilingual Matters.

Banks, J. A. (2002). An introduction to multicultural education (3rd ed.). Boston, MA: Allyn and Bacon.

Bloom, A. (1988). The Closing of the American mind: How higher education has failed democracy and impoverished the souls of today's students. New York, NY: Touchstone Books.

Caney, S. (2002). Equal treatment, exceptions and cultural diversity. In P. Kelly (Ed.), Multiculturalism reconsidered (pp. 81-101). Cambridge, UK: Polity Press.

Cohen, J. (1989). Democratic equality. Ethics, 99(4), 727-751.

Dillon, R. S. (1995). Introduction. In R. S. Dillon (Ed.), Dignity, character, and self-respect (pp. 1-49). New York, NY: Routledge.

Eyal, N. (2005). "Perhaps the most important primary good": Self-respect and Rawls's principles of justice. Politics, Philosophy and Economics, 4(2), 195-219.

Gitlin, T. (1995). The twilight of common dreams: Why America is wracked by culture wars. New York, NY: Henry Holt.

Gutmann, A. (1980). Liberal equality. Cambridge, UK: Cambridge University Press.

Hermes, M. (2005). White teachers, native students: Rethinking culture-based education. In J. Phillion, M. F. He \& F. M. Connelly (Eds.), Narrative and experience in multicultural education (pp. 95-115). Thousand Oaks, CA: Sage Publications.

Huntington, S. P. (2004). Who are we? The challenges to America's national identity. New York, NY: Simon \& Schuster.

Japan Immigration Association (2006). Statistics on the foreigners registered in Japan. Tokyo, Japan: Japan Immigration Association. [Japanese]

Kymlicka, W. (1989). Liberalism, community and culture. Oxford, UK: Oxford University Press. 
Lægaard, S. (2005). On the prospects for a liberal theory of recognition. Res Publica, 11(4), 325-348.

Macedo, S. (2003). Diversity and distrust: Civic education in a multicultural democracy. Cambridge, MA: Harvard University Press.

McKinnon, C. (2003). Basic income, self-respect and reciprocity. Journal of Applied Philosophy, 20(2),143-158.

McKinnon, C. (2006). Toleration: A critical introduction. London, UK: Routledge.

MEXT (2006). Investigation on the present situation of language education for foreign students in Japan [Japanese]. Retrieved from http://www.mext. go.jp/b menu/ houdou/18/04/06042520/001.htm

Morisako, R. (2005). The need of mother tongue education for newcomer children. In Asia-Pacific Human Rights Information Center (Ed.), Education and town designing for multicultural society (pp. 27-51). Osaka, Japan: Buraku Liberation Publishing House. [Japanese]

Moses, M. S. (1997). Multicultural education as fostering individual autonomy. Studies in Philosophy and Education, 16(4), 373-388.

Oguma, E. (1995). The myth of the homogeneous nation. Tokyo, Japan: Shinyosha. [Japanese]

Parekh, B. (1990). The Rushdie affair: Research agenda for political philosophy. Political Studies, 38(4), 695-709.

Peng-Er, L. (2005). At the margins of a liberal-democratic state: Ethnic minorities in Japan. In W. Kymlicka \& B. He (Eds.), Multiculturalism in Asia (pp. 223243). Oxford, UK: Oxford University Press.

Rawls, J. (1971). A theory of justice. Cambridge, MA: The Belknap Press of Harvard University Press.

Rawls, J. (1996). Political liberalism. New York, NY: Columbia University Press.

Rawls, J. (1999). The law of peoples. Cambridge, MA: Harvard University Press.

Schlesinger, Jr., A. M. (1998). The disuniting of America: Reflections on a multicultural society. New York, NY: W. W. Norton \& Company.

Seglow, J. (1998). Universals and particulars: The case of liberal cultural nationalism. Political Studies, 46(5), 963-977.

Spinner-Halev, J. (2001). Feminism, multiculturalism, oppression, and the state. Ethics, 112(1), 84-113.

Tully, J. (1995). Strange multiplicity: Constitutionalism in an age of diversity. Cambridge, UK: Cambridge University Press.

Waldron, J. (1996). Multiculturalism and mélange. In R. K. Fullinwider (Ed.), Public education in a multicultural society: Policy, theory, critique (pp. 90118). Cambridge, UK: Cambridge University Press. 
Weinstock, D. M. (1994). The political theory of strong evaluation. In J. Tully (Ed.), Philosophy in an age of pluralism: The philosophy of Charles Taylor in question (pp. 171-193). Cambridge, UK: Cambridge University Press.

Zaino, J. S. (1998). Self-respect and Rawlsian justice. Journal of Politics, 60(3), 737-753. 